\title{
Prevalence of congenital malformations at the "Les Orangers" Maternity and Reproductive Health Hospital of Rabat: Descriptive study of $\mathbf{4 7 0}$ anomalies
}

KHENATA FORCI ( $\nabla$ docteurforcikhenata@gmail.com )

Universite Mohammed V de Rabat Faculte de Medecine et de Pharmacie Rabat https://orcid.org/00000003-2593-7249

\section{MOHAMED HASSAN ALAMI}

Universite Mohammed V de Rabat Faculte de Medecine et de Pharmacie Rabat

\section{EL ARBI BOUAITI}

Universite Mohammed V de Rabat Faculte de Medecine et de Pharmacie Rabat

\section{MERIEM SLAOUI}

Universite Mohammed V de Rabat Faculte de Medecine et de Pharmacie Rabat

\section{ASSMAA MDAGHRI ALAOUI}

Universite Mohammed V de Rabat Faculte de Medecine et de Pharmacie Rabat

\section{AMAL THIMOU IZGUA}

Universite Mohammed V de Rabat Faculte de Medecine et de Pharmacie Rabat

\section{Research article}

Keywords: Congenital malformation, prevalence, association, antenatal diagnosis, prevention.

Posted Date: November 13th, 2019

DOI: https://doi.org/10.21203/rs.2.17227/v1

License: (c) (i) This work is licensed under a Creative Commons Attribution 4.0 International License. Read Full License

Version of Record: A version of this preprint was published at BMC Pediatrics on June 3rd, 2020. See the published version at https://doi.org/10.1186/s12887-020-02179-6. 


\section{Abstract}

Congenital malformations are described in about $3 \%$ of live births and $20 \%$ of stillbirths. In the industrialized countries, they represent one of the main causes of infant mortality, morbidity and handicap. In our country, as in all developing countries, the prevalence of congenital anomalies is not well known at the national level, besides, causes and risk factors are not always identified. The aim of our work is to conducta the first large descriptive exploratory analysis of congenital malformations cases diagnosed at the "Les Orangers" maternity and reproductive health hospital in Rabat. METHODS We have collected all the cases of congenital malformations diagnosed at the "Les Orangers" maternity and reproductive health hospital in Rabat for a period of five and a half years from January 1st, 2011 to June 30th, 2016. Data were collected on pre-established sheets and on a registry of malformations. Total and specific prevalences were calculated for each malformation then a principal component analysis was conducted followed by a Varimax rotation in order to identify the different associations of malformations in our series. RESULTS During the study period, a total of 43923 births were recorded. We have registred 245 cases of congenital malformations with a prevalence of 5.58 per thousand births of which $19.2 \%$ were fetal deaths in utero. The most representative anomalies were malformations of the osteoarticular system and muscles with a rate of $33 \%$, followed by neurological abnormalities representing $18 \%$, of whom $31 \%$ were hydrocephalus, $26.2 \%$ anencephaly, and $20.24 \%$ spina bifida. Malformations of the eye, ear, face and neck were described in $12 \%$ of the cases, while genetic abnormalities were observed in $8,5 \%$ of which $87.5 \%$ represented Trisomy 21 . The antenatal diagnosis of congenital malformations was performed in $28.6 \%$ of cases. We observed a slight male predominance with a sex ratio of 1.19. CONCLUSIONS Congenital malformations are a real public health problem as they represent a major cause of stillbirth and neonatal mortality. Identifying and studying the causes and risk factors is a priorityin order to adapt a primary prevention strategy, especially folic acid supplementation to prevent neural tube closure defects.

\section{Introduction}

Malformations are often described as congenital defects whether they are diagnosed at birth or later. Thus, the real defects or "primary defects" can be distinguished from distortions and disruptions that are secondary to an extrinsic factor and called "secondary defects". This distinction is essential for establishing genetic counseling, as it allows to evaluate the risk of occurrence or recurrence of the malformation and to propose appropriate prevention.

A congenital malformation (CM) is a morphological abnormality that results from an abnormal development process during the formation of the embryo or fetus. Depending on their type, location and size, malformations can cause functional, psychological, or aesthetic disorders that affect presently more than 8 out of every 1,000 children $[1,2]$.

Congenital malformations account for about $3 \%$ of live births and $20 \%$ of stillbirths. In industrialized countries they represent a frequent cause of infant mortality, morbidity and disability $[3,4,5,6]$. 
According to WHO (World Health Organization), about half of congenital anomalies can not be attributed to a specific cause. Some risk factors or causes are often associated and there are three etiological groups:[7]

- Genetic intrinsic causes (10-15\%): chromosomal, genetic or epigenetic ;

- Extrinsic environmental causes (10-15\%): infectious agents (rubella, toxoplasmosis, cytomegalovirus), physical (ionizing radiation, hyperthermia), medicinal (isotretinoin, thalidomide, antiepileptics), metabolic (maternal diabetes, folic acid deficiency), toxic (tobacco, fetal alcohol syndrome), mechanical (oligoamnios);

- Multifactorial causes (20-25\%)

In our country, as in all developing countries, congenital malformations are one of the leading causes of morbidity and neonatal mortality. According to the results of the last National Survey of Population and Family Health (ENPSF) 2017-2018, the neonatal mortality rate in Morocco is 13.56 per thousand live births with an infant mortality rate (less than one year) of $18 \%$ [8]. Unfortunately, the prevalence of congenital malformations and their causes at the national level is not yet established. Moreover, the risk factors are not always identified.

Consequently, the aim of the present study is to conduct a descriptive exploratory analysis of CM cases diagnosed at the "Les Orangers" maternity and reproductive health hospital in Rabat.

\section{Methods}

\section{Study design}

This is a prospective descriptive epidemiological study of CM cases diagnosed prenatally by obstetrical ultrasound and / or at birth during a routine clinical examination of all newborn infants in the "Les Orangers" maternity hospital and reproductive health of Rabat, Morocco during the period from January $1^{\text {st }}, 2011$ to June $30^{\text {th }}, 2016$. This hospital is a level 3 facility with an average annual delivery rate of 8000 .

All pregnant women whose fetuses or newborns had a malformation, regardless of the term or outcome of the pregnancy, were included.

Cases where the malformation was suspected on obstetrical ultrasound but was postponed at birth were excluded as were the cases of refusal to participate in the survey.

The data were collected on pre-established sheets records and on "Les Orangers" Maternity Malformations Register.

Parents were informed about the terms and objectives of the study and their consent was obtained.

\section{Data collection}


The collection of information was carried out by a doctor and concerned the anamnestic, socioeconomic and biodemographic data of mothers, consanguinity, familial history of malformations, maternal serology, the characteristics of pregnancy and delivery (monitoring, parity, delivery mode, delivery term) and the notion of exposure to teratogenic products (taking drugs and plants or contact with toxic products, habitat close to an industrial plant ... .) and the timing of this exposure in relation to pregnancy. The newborn's biometric data, the status of the newborn at birth, the type and nature of the detected malformation, perinatal care, and short- and medium-term evolution were noted.

To determine the prevalence, we opted for the international definitions used by EUROCAT and the ICBDSR:

- Total prevalence: total number of cases (live births, stillbirths and medical interruptions of pregnancy) divided by the total number of births (live births and stillbirths).

- Prevalence of live births: number of children born alive with the anomaly divided by the total number of live births $[9,10]$.

To classify the malformations we used the following definitions of the types of malformations:

- "Isolated" malformation: any malformation not associated with a chromosomal abnormality or other major abnormality of another system.

- Polymalformations: when there is an association of at least two malformations. They can correspond to three different situations [11]:

1) A sequence: is a set of anomalies in result of a single anomaly or a mechanical factor: example of the sequence oligoamnios or Potter's sequence, following a lack of amniotic fluid.

2) A malformative syndrome: is a set of unrelated abnormalities, all derived from the same cause and not corresponding to a sequence, e.g, Trisomy 21 where all the malformations give the Down syndrome.

3) An association: is the unplanned occurrence of at least two unrecognized malformations as a sequence or syndrome, e.g, VACTER syndrome, acronym for "vertebral, anal, cardiac, tracheal, esophageal, radial and / or renal malformations".

\section{Statistical analysis}

Data entry and statistical analysis was fulfilled using SPSS.18.0 software. Total and specific prevalences were calculated for each malformation. Principal component analysis (PCA) followed by Varimax rotation was performed. The selected factors had a true value greater than 1.25 . The items retained within each factor had a value greater than or equal to 0.40 within the factor and a value less than 0.40 within the other factors. A forced structure with three inter-correlated factors was selected for each malformation.

\section{Results}


During the period of the study, 43923 births were included, of which 245 cases had one or more congenital malformations, which represent a prevalence of 5.58 per thousand births (or 55.8 per 10,000 births). Of these cases, $96.7 \%$ had one or more clinically visible malformations, $51.9 \%$ were males and $43.5 \%$ were females with a sex ratio of 1.19 .

In this series, $470 \mathrm{CM}$ have been reported. Osteoarticular malformations accounted for $33 \%$ followed by neurological malformations with a rate of $18 \%$, abnormalities of the eye, ear, face and neck of which the percentage was $12 \%$. Genetic abnormalities represented $8.5 \%$. (The different types and subtypes of recorded malformations are summarized in Tables 1 and 2 ).

In $26.5 \%$ of our cases, there were polymalformations. Of the 75 newborns who died, there were 33 cases of polymalformative syndrome (44\%).FDIU (fetal death in-utero) was reported in $19.2 \%$ of the cases.

Malformation diagnosis was done prenatally in $28.6 \%$ of cases; of which $5.7 \%$ (4 cases) in the first trimester, $47 \%$ (33 cases) in the second trimester, and $48.5 \%$ (34 cases) in the third trimester. Whereas in more than two thirds of cases $(71.4 \%)$ the diagnosis was made at birth during a systematic clinical examination of newborns.

Factorial analysis has identified a seven-factor structure (associations of malformations) accounting for $21.28 \%$ of the overall variance (Table 3 ). The first three associations accounted for more than $50 \%$ of the total variance.

- The first factor is an association of congenital malformations corresponding to Trisomy 8, pelvic kidney, microphthalmia, sacral agenesis, epidermal sinus, agenesis of nose cartilage and clubfoot.

- The second factor is an association of congenital malformations corresponding to craniosynostosis, pectus excavatum, limb asymmetry, scoliosis, cleft palate and ureteral dilatation.

- The third factor is an association of congenital malformations corresponding to invisible bladder, absence of thalami, thin thorax, limbs in hyperflexion, cardiomegaly, amniotic flanges and polycystic kidney.

\section{Discussion}

In the present study, a prevalence of 5.58 per thousand births $(0.56 \%$ or 55.8 per 10,000 births) was reported. This prevalence is consistent withother African countries, however, it probably does not reflect the reality of the national situation. In fact, the census of CM is not systematically carried out throughout the country and health programs have not integrated routine prenatal screening for $\mathrm{CM}$ and do not consider this problem as a priority at this time. In addition, several malformations may only be revealed after the neonatal period and, therefore, will not be included in our census. Inadequate description of some cases of CM induces global under-reporting of malformations. 
In Congo, a retrospective analytical study in the city of Lubumbashi carried out between 2010 and 2011 across 11 maternity clinics showed a prevalence of 58.4 per 10,000 births (0.58\%) [13]. A similar prevalence $(0.57 \%)$ was also found in a multicenter prospective study conducted at Clinical Universities of Kinshasa [14].

In Egypt, a study conducted between 1995 and 2009 showed a frequency of CM of 2\% [15].

In Nepal, the prevalence of congenital defects was 52.0 per 10,000 [16].

In France, the prevalence of CM at birth is estimated in 3-4\% [17] of live births and this concerns only stillbirths and alive children, whereas early spontaneous abortions are excluded; This makes studying the frequency of congenital anomalies among all pregnancies difficult because most often the etiological diagnosis is not established in case of early abortion.

In Canada, CM affect approximately 3-5\% of newborns [18]. At the same time, in the United States, according to data from the Centers for Disease Control and Prevention (CDC), CM affect one in 33 births, or $3.0 \%$ of all live births [19].

The most frequently reported malformations in our series were:

- Osteoarticular and muscle abnormalities with a rate of 33\% (equivalent to 35 per 10,000 total births), of which $17.4 \%$ of clubfoot, $7.7 \%$ of omphalocele, $7.1 \%$ of supernumerary fingers, followed by short limbs with a rate of $6.4 \%$, and laparoschisis $5.1 \%$. In Egypt, the rate of musculoskeletal abnormalities is $8.82 \%$ (1.8 / 1000) [18]. In Canada, the prevalence of limb malformations is 3.5 per 10,000 total births, and the prevalence of laparoschisis is 4.4 per 10,000 total births in 2009 [15], whereas in our study this rate is 1,8 for 10,000 births.

- $\mathrm{CM}$ of the nervous system with a percentage of $18 \%$ of which $31 \%$ of hydrocephalus $(5.9$ per 10,000 total births), $26.2 \%$ of anencephaly (versus 5 per 10,000 total births), 20, $24 \%$ spina bifida (3.8 per 10,000 total births). Nevertheless, these anomalies are the most frequent malformations in Egypt with a rate of 26.92\% (5.5 / 1000) according to a study conducted between 1995 and 2009 [15].

In our context, the prevalence of neural tube defects is 16.5 per 10,000 total births, whereas in the European Union, the prevalence of neural tube defects (NTDs) decreased by 10.5 per 10,000 total births in 2004 to 9.4 in 2008 [18]. In England and Wales, the prevalence of NTDs remained stable, ranging from 14 to 18 cases per 10,000 total births during the period 1995-2004. In Sweden, the prevalence of spina bifida also decreased from 5.5 per 10,000 during the 1988-1992 period to 2.9 per 10,000 during the period 19992003, mainly due to prenatal diagnosis and termination of pregnancy. [18]. In Nepal, the prevalence of selected NTDs was 4.0 per 10,000 [16].

In the United States, the prevalence of spina bifida increased from 4.2 to 2.9 per 10,000 total births during a mandatory folic acid fortification period (1998-2002) [18]. 
In Canada, the prevalence of neural tube defects has decreased significantly from 7.6 to 4.1 per 10,000 total births between 1996-2007 [18], including spina bifida $(5.5 \rightarrow 2.7)$, anencephaly and similar abnormalities $(1.1 \rightarrow 0.8)$, encephalocele $(1.1 \rightarrow 0.6)$ and this regression is due to folic acid supplementation and prenatal diagnosis.

- Malformations of the eye, ear, face and neck represent $12 \%$ (12.7 per 10,000 total births), of which cranio-facial dysmorphia represent $51.78 \%$ (or $6.610,000$ total births).

- Genetic abnormalities represent $8.5 \%$ (9 per 10,000 total births), $87.5 \%$ of which are Down syndrome (8 per 10,000 total births). In Egypt, these anomalies account for $25 \%$ (5.1 / 1000).

A study conducted in the Rhône-Alpes region over a period of 1981-2009 showed that the most frequently reported malformation is Down syndrome with a prevalence of 28.7 per 10,000 in 2009, and after early detection by bias of antenatal diagnosis the rate of medical termination of pregnancy (MTP) reached $84 \%$ in 2009 with one MTP out of two.

In Canada, Down syndrome has an almost stable prevalence of 14.1 per 10,000 total births between 1998-2007 [18].

- CM of the circulatory system represent in our series a rate of $8,08 \%$ (8,6 per 10,000 total births), against 6,55\% $(0,13 / 1000)$ in Egypt [15].

The prevalence of congenital heart disease in Canada is 85.1 per 10,000 total births (2009), $45 \%$ of which relate to Down syndrome, while in France, the prevalence of congenital heart disease was 83.8 between 2000-2005 [20].

- Genitourinary anomalies are estimated at $7.44 \%$ (8 per 10,000 total births), with $28 \%$ of hypospadias, $28 \%$ of micropenis, and $24 \%$ of ambiguous genitalia. In Egypt, the rate is $18.51 \%$ (3.8 / 1000).

- The cleft lip and cleft palate present a rate of $4.47 \%$ (4.8 per 10,000 total births). This rate reaches $12 \%$ in France. In Canada, the prevalence of cleft lip and palate during the period of 1998-2007 was 16.3 per 10,000 total births [18].

$\mathrm{CM}$ are a source of high mortality. According to the WHO; the number of newborns who die before the age of 28 days due to congenital anomalies is estimated at 276,000 each year [21]. The most common serious congenital anomalies are CM of the heart and neural tube as well as Down syndrome or Trisomy 21.

In our series, the perinatal mortality rate caused by $\mathrm{CM}$ is $30.6 \%$. In developed countries, 20 to $25 \%$ of total perinatal mortality is due to $\mathrm{CM}$, and represent the leading cause of death in France.

In Canada, congenital anomalies affect 8 to $10 \%$ of stillbirths. They accounted for $23.2 \%$ of all deaths of children under the age of 12 months between 2003-2007, including $23.3 \%$ of neonatal deaths, and contributed to an overall infant mortality rate of 5.0 per 1,000 a live births in 2006-2007 [18], [22]. 
In the United States, congenital anomalies are a major cause of infant mortality, accounting for $20.8 \%$ of all infant deaths in 2016 [19].

One-sixth of malformed children are polymalformed. Polymalforms account for $4.5 \%$ of stillborn children and less than $0.5 \%$ of live children [11]. In our study, $26.5 \%$ of malformed persons are polymalforms.

Among the 75 newborns who died, there were 33 cases of polymalformative syndromes, which represents $44 \%, 8$ cases of anencephaly $(10.6 \%), 3$ cases of esophageal atresia ( $4 \%$ ), and 2 cases of thanatophoric dysplasia (2.6\%), 2 cases of laparoschisis (2.6\%) and various isolated cases representing $1.3 \%$ : Dandy walker syndrome, hydrothorax, hydrocephalus, diaphragmatic hernia...

In our study, antenatal diagnosis was performed in $28.6 \%$ of cases, of which $5.7 \%$ (4 cases) in the first trimester, $47 \%$ (33 cases) in the 2nd trimester, and 48.5\% (34 cases) in the third trimester. Whereas in more than two thirds of cases $(71.4 \%)$ the diagnosis was made at birth during a systematic clinical examination of newborns.

In a Parisian study, [23] carried out between 1981 and 2000, prenatal diagnosis has made significant progress in the early detection of congenital malformations, from $16.2 \%(95 \% \mathrm{Cl} 13.8-18.6)$ in 1983 to $69.1 \%(95 \% \mathrm{Cl} 66.7-71.5)$ of the cases in 2000.

In addition, the present study has identified seven groups of malformation associations: (Table 3)

- The first association gathered trisomy 8, pelvic kidney, microphthalmia, sacral agenesis, epidermal sinus, agenesis of the nose cartilage, and clubfoot. We note that in Trisomy 8 , there was a facial dysmorphism that can combine agenesis of the nose cartilage, ophthalmological anomalies with sunken eyes and microphthalmia, urinary abnormalities, bone malformations like sacred agenesis with epidermal sinus and clubfoot.

Also in sacred agenesis or caudal regression syndrome; there is agenesis of the sacro-coccygeal spine, deformation of the pelvis, club feet, renal agenesis or renal ectopia..

- The second group includes craniosynostosis, pectus excavatum, limb asymmetry, scoliosis, cleft palate, and ureteric dilatation; scoliosis is a malformation that can be associated with craniosynostosis, heart, kidney and bone abnormalities in the limbs. Cleft palate is often present in Apert syndrome which is a syndromic form of craniosynostosis.

- The third association includes an invisible bladder, absence of thalami, pectus carinatum, hyperflexion limbs, cardiomegaly, amniotic bridle and polycystic kidney disease. In the case of an invisible bladder (vesical extrophy), we have noted cardio-vascular malformations, renal abnormalities, abnormalities of the limbs and malformations of the central nervous system. These central nervous system malformations, limb and renal malformations are also found in amniotic bridle disease. 
- The fourth association comprised: narrow thorax, craniofacial dysmorphia, microdactyly, and short limbs; these abnormalities can be part of polydactyly syndrome - short ribs - micromelic dwarfism (short limbs, microdactyly), narrow thorax, microcephaly, cardiac, urinary or digestive abnormalities

It can also be part of a dysplasia including a thanatophore dwarfism with prominent forehead macrocephaly that is part of a cranio-facial dysmorphism, narrow chest and short limbs.

- The fifth association includes gingival hypertrophy, macroglossia, exophthalmia, ichthyosis, limb malformation and Dandy Walker syndrome. In congenital ichthyosis, there is ophthalmic impairment, gingival hypertrophy, macroglossia. Some forms of ichthyosis such as Sjögren-Larsson's Syndrome is characterized by neurological involvement.

There are some forms associated with bone involvement such as chondrodysplasia punctata.

- The sixth association includes acardiac fetus, glossoptosis, Pierre Robin syndrome, retrognatism. Pierre Robin's syndrome is characterized by craniofacial anomalies, micro / retrognatism, glossoptosis and respiratory obstruction. It can be isolated or included as part of a polymalformative syndrome. The acardiac fetus acephalic is characterized by primary cardiac dysmorphogenesis with placental vascular anastomoses.

- The seventh association associates canines, deformed thorax, hypertelorism, retrognathism, low-set ears. The natal teeth are part of the clinical picture of more than 50 malformative syndromes of which the most frequent are: Hallerman-Streiff syndrome or ocular-mandibular dyscephaly, Wiedemann-Rautenstrauch syndrome, Elli-van Creveld syndrome, chondroectodermal dysplasia (Ellis Van Creveld syndrome), cranio-facial dysostosis, congenital pachyonychia: rare genodermatosis affecting the ectodermal tissues which is characterized mainly by a thickening of all the nails, labiopalatal clefts, Trisomy 13.

The combination VACTERL / VATER defined by the presence of a set of vertebral malformations, renal and limb abnormalities, is found in the first three associations described in Table 3.

\section{Conclusion}

The present study evaluated the prevalence of $\mathrm{CM}$ at the "Les Orangers" maternal and reproductive health hospital in Rabat, and determined the different types and existing associations of these malformations.

In our context, the primary prevention strategy for $\mathrm{CM}$ should focus on avoiding teratogenic agents, supplementing folic acid in order to prevent neural tube closure abnormalities and managing chronic diseases or those associated with pregnancy. On the other hand, and as secondary prevention, screening and early diagnosis through ultrasound is required, followed by treatment and management of an existing disorder to reduce and prevent morbidity. 
Furthermore, the registration and monitoring of $\mathrm{CM}$ in our country should be established as a whole program with a congenital anomalies registry as part of the national health information system and a teratovigilance network. By considering a national strategy and / or regional antenatal diagnosis, genetic counseling and prevention of $\mathrm{CM}$ and to allow better management of newborns with congenital anomalies at birth.

\section{List Of Abbreviations}

CM: Congenital malformations

WHO: World health organization

ENPSF: National Survey of Population and Family Health

EUROCAT: European surveillance of congenital anomalies

ICBDSR: International clearinghouse for birth defects surveillance and research

VACTER/VATER: acronym for vertebral, anales, cardiac, tracheal, œsophagial, radiales, and/or renal malformations

PCA: Principal component analysis

FDIU: Fetal death in-utero

CDC: Centers for Disease Control and Prevention

NTDs: Neural tube defects

MTP: Medical termination of pregnancy

Cl: confidence interval

ICD: International classification of diseases

\section{Declarations}

\section{Ethical approval and consent to participate}

The Ethical Committee of Biological Research, Faculty of Medicine and Pharmacy - Rabat, approved the study. Oral consent to participate was obtained from the parents.

\section{Consent for publication}

Not applicable 
Availability of data and materials

Data is available upon reasonable request.

Competing interests

The authors declare that they have no competing interests.

Funding

Not applicable

Authors'contributions

All the authors have approved the present version of the manuscript.

Acknowledgments

We would like to thank everyone who had contributed in this study.

\section{References}

1. REMERA: Registre des malformations en Rhône Alpes, Situation du registre en 2011, Rapport d’activités. (Données naissances 2010)

2. Les malformations congénitales en Rhône-Alpes : Les dossiers santé-environnement de l'ors Août 2012 - n8, Observatoire Régional de la Santé Rhône-Alpes

3. Hatton F, Bouvier-Colle MH, Blondel B, Pequignot F, Letoullec A. Evolution de la mortalité infantile en France: fréquence et causes de 1950 à 1997. Arch Pédiatr 2000; 7: 239-244.DOI: 10.1016/s0929$\underline{693 x}(\underline{00}) \underline{80004-1}$

4. Lee k, Khoshnood B, Chen L, Wall SN, Cromie WJ, Mittendor RL. Infant mortality from congenital malformations in the United States, 1970-1997. ObstetGynecol 2001; 98:620-629.

5. Liu S, Joseph KS, Kramer MS, Allen AC, Sauve R, Rusen ID, Wen SW, fetal and Infant Health Study Group of the Canadien Perinatal Surveillance system. Relationship of prenatal diagnosis and pregnancy termination to overall infant mortality in Canada. JAMA 2002; 287:1561-1567.

6. Waitzman NJ, Romano PS, Scheffler RM. Estimates of the economic costs of birth defects. Inquiry 1994;31:188-205

7. Stevenson RE. Human Malformations and related anomalies. New York University Press, 1993, p 115.

8. Enquête Nationale sur la Population et la Santé Familiale (ENPSF) - 2018, Rapport Préliminaire, Ministère de la Santé, DPRF/DPE/SEIS, Rabat, Maroc

9. Bérénice DORAY. Epidémiologie, clinique, génétique et prévention des malformations congénitales, Registre des malformations congénitales d’Alsace 1995-2009. Thèse, Université de Strasbourg, 
ECOLE DOCTORALE des sciences de la vie et de la santé, 25 Juillet 2013

10. Lelong, A-C. Thieulin, V. Vodovar, F. Goffınet, B. Khoshnood.Surveillance épidémiologique et diagnostic prénatal des malformations congénitales en population parisienne: évolution sur 27 ans, 1981-2007. Archives de Pédiatrie $2012 ; 19: 1030-1038$

11. Pathologie du développement: malformations congénitales 2011-2012. CollègeFrançais des Pathologistes (CoPath).

12. CIM-10 FR, classification statistique internationale des maladies et des problèmes de santé connexes. Rapport de la conférenceinternationale, volume 1, édition 2017

13. LubalaKasole Toni. ETUDE DES MALFORMATIONS CONGENITALES CLINIQUEMENT VISIBLES A LA NAISSANCE A LUBUMBASHI.Mémoire, Université de Lubumbashi, Faculté de Médecine, année 20102011

14. Tabu G. Profil des malformations congénitales apparentes à Kinshasa. Mémoire de Spécialisation, 2004, Université de Kinshasa.

15. Shawky, Doaa I. Sadik. Congenital malformations prevalent among Egyptien children and associated risk factors. The Egyptian Journal of Medical Human Genetics (2011) 12, 69-78

16. Shiva Bhandari, Jamuna Tamrakar Sayami, Ricky Raj K.C. and Megha Raj Banjara. Prevalence of congenital defects including selected neural tube defects in Nepal: results from a health survey. BMC Pediatrics (2015) 15:133. DOI 10.1186/s12887-015-0453-1

17. Catherine De Vigan, BabakKhoshnood, Erwan Cadio, Véronique Vodovar, François Goffinet.Le Registre des malformations de Paris : un outil pour la surveillance des malformations et l'évaluation de leur prise en charge, Inserm, UMR S149, IFR 69, Unité de recherche épidémiologique en santé périnatale et santé des femmes, Paris, France, UPMC, Université Paris 6, UMR S149, Paris, France. BEH thématique 28-29 / 8 juillet 2008

18. Dr Gregory Taylor. Les anomalies congénitales au CANADA 2013, Rapport de surveillance sur la santé périnatale. Agence de la santé publique du CANADA, Ottawa, Septembre 2013.

19. Mimi T. Le, Charlie J. Shumate, Adrienne T. Hoyt, Anna V. Wilkinson, Mark A. Canfield. The prevalence of birth defects among non-Hispanic Asian/Pacific Islanders and American Indians/Alaska Natives in Texas, 1999-2015, Birth Defects Research. $2019 ; 1-9$

20. Congénital Heart Defects in Europe, 2000-2005. Special rapport, EUROCAT 2009.

21. Anomalies congénitales : OMS (Aide-mémoire) N³70, Avril 2015

22. Agence de la santé publique du Canada. Indicateurs de la santé périnatale au Canada 2011. Ottawa: Agence de la santé publique du Canada, 2012.

23. De Vigan, B. Khoshnood, A. Lhomme, V. Vodovar, J. Goujard, F. Goffinet. Prévalence et diagnostic prénatal des malformations en population parisiènne, vingt ans de surveillance par le Registre des malformations congénitales de Paris (évolution sur 20 ans). 2005, J Gynecol Obstet Biol Reprod 2005, 34 (cahier 1) : 8-16 


\section{Tables}

Table 1: The different types of congenital malformations according to the International Classification ICD-10 [12]

\begin{tabular}{lc}
\hline $\begin{array}{l}\text { Types of congenital malformations according to the International } \\
\text { Classification ICD-10 }\end{array}$ & $\begin{array}{c}\text { Prevalence compared to all malformations } \\
\text { in percentage }\end{array}$ \\
\hline Q00-Q07 Congenital malformations of the nervous system & 18 \\
Q10-Q18 Congenital malformations of eye, ear, face and neck & 12 \\
Q20-Q28 Congenital malformations of the circulatory system & 8 \\
Q30-Q34 Congenital malformations of the respiratory system & 1 \\
Q35-Q37 Cleft lip and cleft palate & 4.5 \\
Q38-Q45 Congenital malformations of the digestive system & 4 \\
Q50-Q64 Congenital malformations of genitourinary system & 7.5 \\
Q65-Q79 Congenital malformations and deformations of the & 33 \\
musculoskeletal system & 4 \\
Q80-Q89 Other congenital malformations & 8.5 \\
Q90-Q99 Chromosomal abnormalities & 4 \\
\hline
\end{tabular}

International Statistical Classification of Diseases and Related Health Problems 10th Revision (ICD-10)-WHO Version for; 2016

Table 2: Prevalence of types and subtypes of congenital malformations identified at "Les Orangers" Maternity and Reproductive Health Hospital of Rabat,_Morocco 


\begin{tabular}{|c|c|c|c|}
\hline $\begin{array}{l}\text { Types and subtypes of congenital malformations according to } \\
\text { classification (ICD-10) }\end{array}$ & No./470 & $\%$ & $\begin{array}{l}\text { Total prevalence per } 10,000 \\
\text { live births }\end{array}$ \\
\hline \multicolumn{4}{|l|}{ Q00-Q07 Congenital malformations of the nervous system } \\
\hline Hydrocephalus (Q03.9) & 26 & 31 & 5.9 \\
\hline Anencephaly (Q00) & 22 & 26.2 & 5 \\
\hline Spina-bifida (Q05.9) & 17 & 20.24 & 3.8 \\
\hline Encephalocele (Q01.9) & 5 & 6 & 1.14 \\
\hline Microcephaly (Q02) & 4 & 4.76 & 0.9 \\
\hline Holoprosencephaly (Q04.2) & 4 & 4.76 & 0.9 \\
\hline Dandy Walker syndrome (Q03.1) & 2 & 2.4 & 0.45 \\
\hline Arnold Chiari syndrome (Q07.0) & 1 & 1.2 & 0.2 \\
\hline Facial paralysis (Q07.8) & 1 & 1.2 & 0.2 \\
\hline Agenesis of corpus callosum (Q04.0) & 1 & 1.2 & 0.2 \\
\hline Absence of Thalami* & 1 & 1.2 & 0.2 \\
\hline Total & 84 & 100.00 & 19 \\
\hline \multicolumn{4}{|l|}{ Q10-Q18 Congenital malformations of the eye, ear, face \& neck } \\
\hline Craniofacial dysmorphism* & 29 & 51.78 & 6.6 \\
\hline Short neck* & 6 & 10.7 & 1.3 \\
\hline Retrognatism* & 6 & 10.7 & 1.3 \\
\hline Low-set ears (Q17.4) & 6 & 10.7 & 1.3 \\
\hline Exophtalmia (=Macrophtalmos) (Q11.3) & 3 & 5.35 & 0.7 \\
\hline Microphtalmos (Q11.2) & 1 & 1.8 & 0.2 \\
\hline Congenital glaucoma(Q15.0) & 1 & 1.8 & 0.2 \\
\hline Bulging Front* & 1 & 1.8 & 0.2 \\
\hline congenital absence of auricle (Q16.0) & 1 & 1.8 & 0.2 \\
\hline Canines* & 1 & 1.8 & 0.2 \\
\hline Gumtooth* & 1 & 1.8 & 0.2 \\
\hline Total & 56 & 100.00 & 12.7 \\
\hline \multicolumn{4}{|l|}{ Q20-Q28 Congenital malformations of the circulatory system } \\
\hline Congenital valve malformation* & 10 & 26.31 & 2.2 \\
\hline Hydrops fetalis ${ }^{*}$ & 7 & 18.42 & 1.6 \\
\hline Cardiomegaly* & 5 & 13.15 & 1.1 \\
\hline Cystic hygroma* & 5 & 13.15 & 1.1 \\
\hline Single umbilical artery(Q27.0) & 4 & 10.52 & 0.9 \\
\hline Hydrothorax* & 2 & 5.3 & 0.45 \\
\hline Laevocardia (Q24.1) & 1 & 2.63 & 0.2 \\
\hline Tetralogy of Fallot (Q21.3) & 1 & 2.63 & 0.2 \\
\hline Cardiomyopathy (Q24.9) & 1 & 2.63 & 0.2 \\
\hline Single umbilical artery(Q27.0) & 1 & 2.63 & 0.2 \\
\hline 2 arteries +2 veins* & 1 & 2.63 & 0.2 \\
\hline Total & 38 & 100.00 & 8.6 \\
\hline \multicolumn{4}{|l|}{ Q30-Q34 Congenital malformations of the respiratory system } \\
\hline Agenesis of nose cartilage (Q30.1) & 2 & 40 & 0.45 \\
\hline Hypoplasia and dysplasia of lung(Q33.6) & 2 & 40 & 0.45 \\
\hline Agenesis of lung(Q33.3) & 1 & 20 & 0.2 \\
\hline Total & 5 & 100.00 & 1.1 \\
\hline \multicolumn{4}{|l|}{ Q35-Q37 Cleft lip and clift palate } \\
\hline Cleft palate with cleft lip (Q37.-) & 9 & 42.86 & 2 \\
\hline Cleft lip(Q36.-) & 7 & 33.33 & 1.6 \\
\hline Cleft palate (Q35.-) & 3 & 14.3 & 0.6 \\
\hline Alveolar cleft* & 1 & 4.76 & 0.2 \\
\hline Velopalatine cleft $*$ & 1 & 4.76 & 0.2 \\
\hline Total & 21 & 100.00 & 4.8 \\
\hline \multicolumn{4}{|l|}{ Q38-Q45 Congenital malformations of the digestive system } \\
\hline Atresia of oesophagus (Q39.0) & 6 & 33.33 & 1.3 \\
\hline Hépatomegaly (Q44.7) & 3 & 16.7 & 0.6 \\
\hline Imperforate anus (Q42.3) & 2 & 11.11 & 0.45 \\
\hline Anal malformation(Q43.9) & 2 & 11.11 & 0.45 \\
\hline Hypertrophied gums (Q38.6) & 1 & 5.55 & 0.2 \\
\hline
\end{tabular}




$\begin{array}{cc}5.55 & 0.2 \\ 5.55 & 0.2 \\ 5.55 & 0.2 \\ 5.55 & 0.2 \\ 100.00 & 4.1\end{array}$

Macroglossia (Q38.2)

Glossoptosis *

Congenital dilatation of the colon (Q43.9)

Total

\section{Q50-Q56 Congenital malformations of genital organs}

Hypospadias (Q54.9)

Micropenis (Q55.6)

Ambiguous genitalia (Q56.4)

Cryptorchism (Q53.9)

Invisible clitoris (Q52.6)

Congenital malformation of female genitalia(Q52.9)

Total

Q60-Q64 Congenital malformations of the urinary system

Polycystic kidney (Q61.3)

Ureterohydronephrosis (Q62.-)

Epispadias (Q64.0)

Absence of bladder(Q64.5)

Congenital dilatation of ureter(Q62.2)

Pelvic kidney(Q63.2)

Total

Q65-Q79 Congenital malformations and deformations of the musculoskeletal system

Clubfoot (Q66.8)

Omphalocele (Q79.2)

Polydactyly (Q69.0)

Short limbs (Q73.8)

Gastroschisis (Q79.3)

Chondrodysplasia punctata (Q77.3)

Talipes equinovarus (Q66.0)

Macrocephaly(Q75.3)

Prune Belly syndrome (Q79.4)

Syndactyly (Q70.-)

Toe agenesis*

Feet valgus (Q66.6)

Clinodactyly*

Fingers agenesis*

Limb malformation (Q74.9)

Thanatophore dwarfism*

Craniosynostosis (Q75.0)

Hypertelorism (Q75.2)

Hyperlaxity ligament*

Congenital absence of limbs (Q73.0)

Forearm agenesis*

Foot agenesis*

Limbs in hyperflexion*

Limbs asymmetry*

Congenital dislocation of hip(Q65.2)

Scoliosis (Q67.5)

Caudal regression syndrome*

Diaphragmatic hernia(Q79.0)

Narrow thorax (Q67.8)

Pectus carinatum (Q67.7)

Deformed thorax (Q76.9)

Amniotic bridle*

Microdactyly*

Hand agenesis*

Phalanges agenesis*

Thumb hypoplasia*

Club hand*

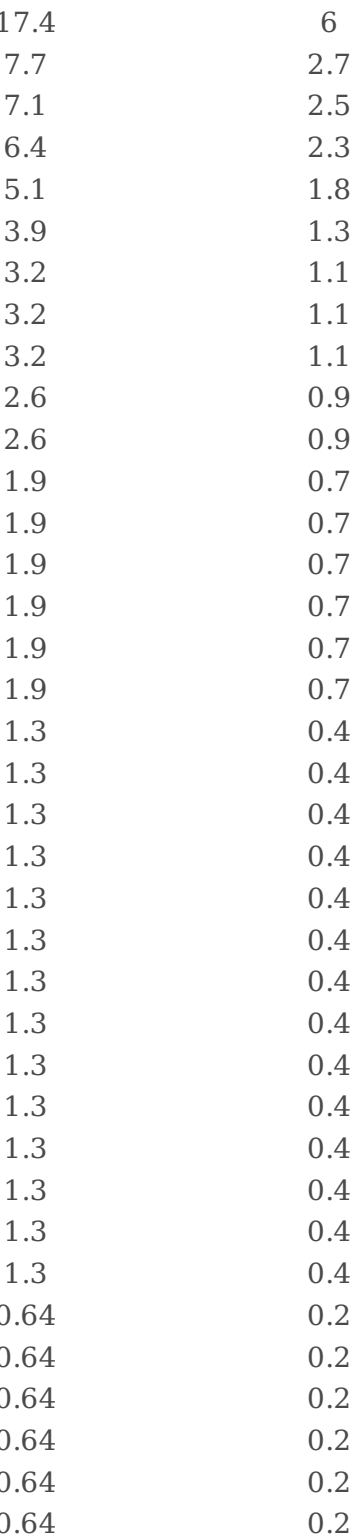


Bone growth*

$\begin{array}{ccc}1 & 0.64 & 0.2 \\ 1 & 0.64 & 0.2 \\ 1 & 0.64 & 0.2 \\ 1 & 0.64 & 0.2 \\ 1 & 0.64 & 0.2 \\ 1 & 0.64 & 0.2 \\ 155 & 100.00 & 35\end{array}$

Spine agenesis*

Sarcum agenesis*

Parieto-occipital bone agenesis*

Pectus excavatum (Q67.6)

Malformation of ribs(Q76.6)

Total

Q80-Q89 Other congenital malformations

Ichtyosis vulgaris (Q80.0)

Cervico-facial hemolymphangioma*

Congenital splenomegaly (89.0)

Alopecia (Q84.0)

Naevus (Q82.5)

Epidermal sinus*

Depigmentation*

Situs inversus (Q89.3)

Absence of Wharton's Jelly around the umbilical arteries*

Pierre Robin syndrome (Q87.0)

Acardiac fetus acephalic*

Absence of gluteal fold*

Cyclopia (Q87.0)

Ombilical hernia*

Total

Q90-Q99 Chromosomal abnormalities

Trisomy 21 (=Down syndrome) (Q90.-)

Trisomy 13 (Q91.7)

Trisomy 18 (Q91.3)

Trisomy 8 (Q92.1)

Senior Loken syndrome*

Total

\begin{tabular}{ccc}
3 & 16.7 & 0.7 \\
2 & 11.11 & 0.4 \\
2 & 11.11 & 0.4 \\
1 & 5.55 & 0.2 \\
1 & 5.55 & 0.2 \\
1 & 5.55 & 0.2 \\
1 & 5.55 & 0.2 \\
1 & 5.55 & 0.2 \\
1 & 5.55 & 0.2 \\
1 & 5.55 & 0.2 \\
1 & 5.55 & 0.2 \\
1 & 5.55 & 0.2 \\
1 & 5.55 & 0.2 \\
1 & 5.55 & 0.2 \\
18 & 100.00 & 4 \\
& & \\
35 & 87.5 & 8 \\
2 & 5 & 0.4 \\
1 & 2.5 & 0.2 \\
1 & 2.5 & 0.2 \\
1 & 2.5 & 0.2 \\
40 & 100.00 & 9 \\
\hline
\end{tabular}

No: Number of cases; \%: percentage; *: Congenital malformations not found in the ICD-10 classification

Table 3: Analysis of congenital malformations profiles detected at the "Les Orangers" Maternity and Reproductive Health Hospital,_Rabat,_Morocco. 


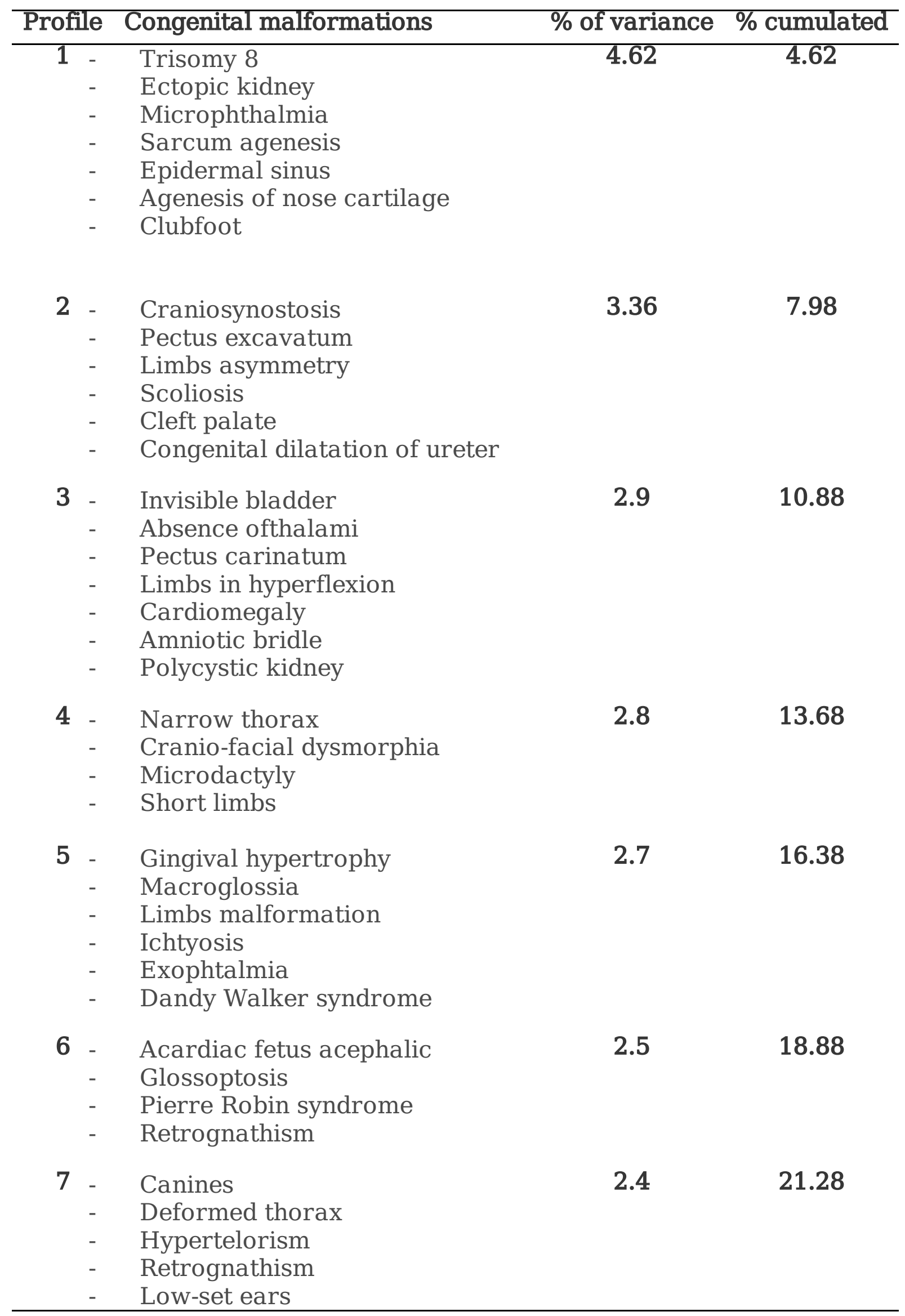

$\%=$ percentage 